\title{
Influence of amygdalin on PDG, IGF and PDGFR expression in HSC-T6 cells
}

\author{
HUANHUAN LUO ${ }^{1}$, FANG ZHAO ${ }^{2}$, FENGXUE ZHANG ${ }^{1}$ and NI LIU ${ }^{2}$ \\ ${ }^{1}$ School of Basic Medical Sciences; ${ }^{2}$ Department of Tropical Medicine, \\ Guangzhou University of Chinese Medicine, Guangzhou, Guangdong 510006, P.R. China
}

Received September 12, 2016; Accepted May 15, 2017

DOI: $10.3892 /$ etm.2018.5886

\begin{abstract}
The aim of the present study was to elucidate the mechanism of amygdalin treatment on reducing liver fibrosis by investigating its role in regulating the expression level of platelet-derived growth factor (PDGF), insulin-like growth factor (IGF) and PDGF receptor (PDGFR) in the hepatic stellate cell (HSC)-T6 line. HSC-T6 cells were used as an in vitro model and randomly assigned into four groups: control, high-dose amygdalin, mid-dose amygdalin and low-dose amygdalin. Following amygdalin treatment, compared with the control, a high dose of amygdalin significantly suppressed the mRNA expression of PDGF and IGF (each $\mathrm{P}<0.05$ ), whereas moderate and low doses showed no significant effect, relatively low doses of amygdalin are not sufficient to transfer signals to its receptor. The high-dose amygdalin and low-dose amygdalin displayed suppressed protein expression of PDGF at 24, 48 and $72 \mathrm{~h}$, with the high-dose group exhibiting the most marked suppression at all three time points. By reducing the transcription of PDGF and IGF mRNA and the expression of PDGF protein, amygdalin decreased the synthesis and release of PDGF and IGF, thereby reducing the influence of PDGF and IGF on HSCs, thus protecting the liver from fibrosis.
\end{abstract}

\section{Introduction}

Hepatic fibrosis is a wound healing response to a variety of chronic stimuli that results in the excessive production and deposition of extracellular matrix (ECM) in the liver (1). Hepatic stellate cells (HSCs) are the central link and the cytological basis of liver fibrosis. The activation of HSCs is a well-accepted critical event in hepatic fibrosis and an attractive target for treatment. Activated HSCs are able to secrete

Correspondence to: Dr Huanhuan Luo, School of Basic Medical Sciences, Guangzhou University of Chinese Medicine, Jichu building, 423 Waihuan road, University town, Guangzhou, Guangdong 510006, P.R. China

E-mail: avenluo@gzucm.edu.cn

Key words: amygdalin, anti-fibrosis, HSC-T6, insulin-like growth factor, platelet-derived growth factor various cytokines, including transforming growth factor (TGF)- $\beta$ and platelet-derived growth factor (PDGF), which act as regulators of various different signaling transduction pathways in the formation of liver fibrosis (2). PDGF, which is one of the most effective mitogens in terms of exerting functions on HSCs, regulates liver fibrosis via autocrine and paracrine signaling throughout the entire HSC activation process (3). A previous study demonstrated that PDGF was able to promote insulin-like growth factor (IGF)-1, secretion and the release of IGF binding proteins in HSC cells and therefore induce liver fibrosis via PDGF self-interaction (4). HSCs are also the primary cell type responsible for the progression of liver fibrosis and serve a central role in the pathogenesis of liver fibrosis (5). The HSC-T6 immortal cell line is established by transfecting rat HSCs with the SV40 virus and has the phenotype of activated HSC and can virtually be pass aged infinitely (5). In the present study, HSC-T6 was used as a cell model to investigate the role of amygdalin in regulating the mRNA expression levels of PDGF and IGF and the protein expression levels of PDGF and its receptor (PDGFR).

\section{Materials and methods}

Experimental cells. The HSC-T6 cell line was cryopreserved and resuscitated by the Institute of Tropical Medicine, Guangzhou University of Chinese Medicine (Guangzhou, China).

Experimental drugs. Amygdalin (molecular weight, 457.4; cat. no. 110820-200403; $20 \mathrm{mg} /$ tube) was purchased from the National Institute for the Control of Pharmaceutical and Biological Products (Beijing, China). The storage solution was prepared by diluting amygdalin in water to a concentration of $10^{-5}, 10^{-4}$ and $10^{-3} \mathrm{~mol} / \mathrm{l}$. The solution then under intermittent sterilization at a low-temperature $\left(4^{\circ} \mathrm{C}\right)$ and was preserved at $-20^{\circ} \mathrm{C}$ for future use. Prior to experiments, the stocking solution was prepared by diluting the storage solution with Dulbecco's modified Eagle's medium (DMEM; Gibco; Thermo Fisher Scientific, Inc., Waltham, MA, USA) to a concentration of $20 \mathrm{mmol} / 1$, followed by sterilization with microporous membranes and preservation at $-20^{\circ} \mathrm{C}$.

Chemical reagents. The following chemical reagents were used in the present study: High-glucose DMEM (Gibco; Thermo 
Fisher Scientific, Inc.); fetal bovine serum (FBS; Hangzhou Sijiqing Biological Engineering Materials Co., Ltd., Hangzhou, China); L-glutamine, dimethyl sulfoxide, trypsin acrylamide, pancreatic enzymes, methanol and Tris-base (Sigma-Aldrich; Merck KGaA, Darmstadt, Germany); EDTA (Shanghai Shenggong Biology Engineering Technology Service, Ltd., Shanghai, China); penicillin and streptomycin (North China Pharmaceutical Co., Ltd., Shijiazhuang, China); RNA extraction kit, RNA reverse transcription kit, dNTP, RNase inhibitor and oligo-dT (Tiangen Biotech Co., Ltd., Beijing, China); DNA marker, polymerase chain reaction (PCR) kit and optimized PCR kit (Tiangen Biotech Co., Ltd.); protein extraction kit (cat. no. DB1011; Bioscience Co., Ltd., Shanghai, China); bovine serum albumin (Shanghai Pufei Biotech Co., Ltd., Shanghai, China); nitrocellulose membrane and filter paper (Whatman; GE Healthcare Life Sciences, Shanghai, China); horseradish peroxidase-conjugated secondary antibody (cat. no. 365802; Santa Cruz Biotechnology, Inc., Dallas, TX, USA); antibodies against PDGF(cat. no. 360511; Bioworld Technology, Inc., St.Louis Park, MN,USA); fluorescein isothiocyanate secondary antibody (1:100; cat. no. 375702; Santa Cruz Biotechnology, Inc.) and antibodies against PDGFR- $\alpha$ (cat. no. 361162) and PDGFR- $\beta$ (cat. no. 360924; Bioworld Technology, Inc.).

Equipment. The following instruments were used in the present study: Clean bench (cat. no. YJ-875; Suzhou Purification Engineering Installation Co.,Ltd., Suzhou, China,); cell culture flask (Corning Incorporated, Corning, NY, USA); cell counting slice and millipore filter $(0.45$ and $0.2 \mu \mathrm{m}$, respectively; Shanghai Peninsula Industrial Co., Ltd, Shanghai, China); fluorescence microscope (Leica Microsystems, Inc., Buffalo Grove, IL, USA); inverted microscope (BX600; Olympus Corporation, Tokyo, Japan); $-86^{\circ} \mathrm{C}$ cryogenic refrigerator (Revco; Thermo Fisher Scientific, Inc.); incubator (2300-2E; Sheldon Manufacturing, Inc., Cornelius, OR, USA); microplate reader (ELX800; BioTek Instruments, Inc., Winooski, VT, USA); PCR amplifier (Revco; Thermo Fisher Scientific, Inc.); homogenizer (Ningbo Scientz Biotechnology Co., Ltd., Ningbo, China); pipette (Eppendorf, Hamburg, Germany); film analysis system (Tanon Science and Technology Co., Ltd., Shanghai, China); ultraviolet spectrophotometer (Hach Company, Loveland, CO, USA); electrophoresis system (Bio-Rad Laboratories, Inc., Hercules, CA, USA); and flow cytometer (Beckman Coulter, Inc., Brea, CA, USA).

Cell treatment. The HSC-T6 immortal cell line, which has unlimited passing characteristics, was generated by transfecting SV40 virus into rat HSC cells. The transfected HSC-T6 cell line was purchased from the Type Culture Collection of the Chinese Academy of Sciences (Shanghai, China). HSC-T6 cells $\left(1 \times 10^{6}\right.$ cells/well $)$ were planted in a 6 -well plate and incubated at $37^{\circ} \mathrm{C}$ with $5 \% \mathrm{CO}_{2}$ for $24 \mathrm{~h}$ and DMEM containing $5 \%$ FBS. The cells were subsequently allowed to attach and following growth to $50 \%$ confluence, the medium was replenished. HSC-T6 cells were then randomly divided into four groups and incubated with different amounts of amygdalin as follows: Control (DMEM containing 2\% FBS), low dose $\left(10^{-5} \mathrm{~mol} / \mathrm{l}\right)$, mid dose $\left(10^{-4} \mathrm{~mol} / \mathrm{l}\right)$ and high dose $\left(10^{-3} \mathrm{~mol} / \mathrm{l}\right)$ at $37^{\circ} \mathrm{C}$ and $5 \% \mathrm{CO}_{2}$ for $48 \mathrm{~h}$. Amygdalin in each treatment group was dissolved in DMEM containing $2 \%$ FBS.
RNA extraction. Amygdalin treatment was administered as aforementioned and three repeats were performed for each group. Following $48 \mathrm{~h}$ drug treatment, cells were digested and the total RNA was extracted using a TRIzol reagent (Invitrogen; Thermo Fisher Scientific, Inc.) according to the manufacturer's protocol. Briefly, $1 \mathrm{ml}$ lysis buffer was added to cells, mixed and allowed to stand for $5 \mathrm{~min}$. Subsequently $200 \mu \mathrm{CHCl}_{3}$ was added, the mixture was vortexed for $30 \mathrm{sec}$, allowed to stand for $10 \mathrm{~min}$ and centrifuged at a speed of $14,800 \mathrm{x} \mathrm{g}$ for $10 \mathrm{~min}$ at $4^{\circ} \mathrm{C}$. The supernatant was collected and added to $1 / 2$ (vol/vol) ethanol, allowed to stand for $2 \mathrm{~min}$ and centrifuged at a speed of $14,800 \mathrm{x} \mathrm{g}$ at $4^{\circ} \mathrm{C}$ for $30 \mathrm{sec}$. Subsequently, $0.5 \mathrm{ml}$ deproteinized buffer was added and the mixture was allowed to stand for $2 \mathrm{~min}$, at which point the mixture was again centrifuged at a speed of $14,800 \mathrm{x} \mathrm{g}$ at $4^{\circ} \mathrm{C}$ for $30 \mathrm{sec}$. The precipitate was added to $0.7 \mathrm{ml}$ wash buffer, allowed to stand for $2 \mathrm{~min}$, followed by centrifuging at $14,800 \mathrm{x} \mathrm{g}$ at $4^{\circ} \mathrm{C}$ for $30 \mathrm{sec}$. This washing step was repeated twice. RNA was collected following centrifuging the isolation column at a speed of $14,800 \mathrm{xg}$ at $4^{\circ} \mathrm{C}$ for $2 \mathrm{~min}$ and air-drying for $10 \mathrm{~min}$. Then, $50 \mu \mathrm{l}$ RNase-free water was added to the collected RNA, allowed to stand for 2 min and centrifuged again at $14,800 \mathrm{xg}$ at $4^{\circ} \mathrm{C}$. The supernatant was stored at $-70^{\circ} \mathrm{C}$ prior to further use.

Reverse transcription-quantitative PCR (RT-qPCR). The expression profiles of PDGF and IGF were measured using a one-step SYBR PrimeScript RT-PCR kit (Takara Bio, Inc., Otsu, Japan) in an ABI Prism 7500 (Applied Biosystems; Thermo Fisher Scientific, Inc.) following the manufacturer's protocol. An RNA reverse transcription kit, dNTP, RNase inhibitor and oligo-dT (all Tiangen Biotech Co., Ltd., Beijing, China) were used for RT-qPCR. The $20 \mu 1$ reaction mixture contained $4 \mu \mathrm{l}$ cDNA, $2 \mu \mathrm{l}$ 10X buffer, $0.4 \mu \mathrm{l}$ dNTP (10 mol/l), $0.4 \mu 1$ primer mix and $0.5 \mathrm{U}$ Taq polymerase and $\mathrm{dd}_{2} \mathrm{O}$. The qPCR procedure was as follows: Initial denaturation at $94^{\circ} \mathrm{C}$ for $2 \mathrm{~min}$, followed by 30 cycles of denaturation at $94^{\circ} \mathrm{C}$ for $30 \mathrm{sec}$, annealing at $58^{\circ} \mathrm{C}$ for $30 \mathrm{sec}$ and elongation at $72^{\circ} \mathrm{C}$ for $45 \mathrm{sec}$, with a final elongation at $72^{\circ} \mathrm{C}$ for $10 \mathrm{~min}$ and short storage at $4^{\circ} \mathrm{C}$. The primer sequences utilized in RT-qPCR were as follows: PDGF, forward, 5'-GATCCGCTC CTTTGATGATC-3' and reverse, 5'-GTCTCACACTTGCAT GCCAG-3'; IGF, forward 5'-AAGCCTACAAAGTCAGCT CC-3' and reverse, 5'-CGTCTTGTTTCCTGCACTTC-3'; and $\beta$-actin, forward, 5'-TGGTGGGTATGGGTCAGAAGGACT C-3' and reverse, 5'-CATGGCTGGGGTGTTGAAGGTCTC A-3'. All primers were synthesized by Invitrogen; Thermo Fisher Scientific, Inc. The relative expression was analyzed using the $2^{-\Delta \Delta C q}$ method (6) and the expression of all transcripts were normalized to that of the housekeeping gene $\beta$-actin.

Western blotting. Whole-cell lysates were isolated using radioimmunoprecipitation assay lysis buffer (Thermo Fisher Scientific, Inc.) and proteins were extracted using a BCA protein assay kit (Thermo Fisher Scientific, Inc.) following the manufacturer's protocol. The PDGF protein was analyzed using western blotting as previously described (7). For electrophoresis, $15 \%$ SDS-PAGE was prepared by mounting glass slides with $0.75-\mathrm{mm}$ comb and injecting the solution from the side. The gel was allowed to solidify at room temperature 
for 30-45 min and protein samples were loaded following boiling for 3-5 min. Electrophoresis was performed under $110 \mathrm{~V}$ for $60 \mathrm{~min}$ and the gel was subsequently removed from the rack and balanced with the transfer buffer at room temperature for $30 \mathrm{~min}$. Also, a nitrocellulose membrane was placed (at a $45^{\circ}$ angle) into the transfer buffer and balanced for 10-15 min. The membrane was placed on the gel, bubbles were removed and the transfer device was locked and placed into the electrophoresis rack with each electrode connected properly. Transmembrane electrophoresis was performed under $100 \mathrm{~V}$ for $60 \mathrm{~min}$. Following protein transfer, the membrane was incubated at $4^{\circ} \mathrm{C}$ with the $5 \mathrm{ml}$ blocking buffer and the PDGF monoclonal antibody (1:100; cat. no. 360511; Bioworld Technology, Inc.) overnight and then incubated with horseradish peroxidase-conjugated secondary antibodies (1:100) at room temperature for $1 \mathrm{~h}$. Immunoreactive bands were detected by enhanced chemiluminescence (ECL) reagent (Pierce; Thermo Fisher Scientific, Inc.), visualized by autoradiography and quantified using the Quantity One analysis system (version 4.4.02; Bio-Rad Laboratories, Inc.). $\beta$-actin (1:100; cat. no. 390521; Bioworld Technology, Inc.) was utilized as the internal control.

Flow cytometry. Cells were routinely cultured, digested using $0.25 \%$ pancreatic enzymes and $0.25 \%$ EDTA and washed with PBS prior to centrifugation at $200 \mathrm{x}$ g at $4^{\circ} \mathrm{C}$ for $5 \mathrm{~min}$. The cells were blocked using $1 \%$ BSA (Pierce, Thermo Fisher Scientific, Inc.) at $4^{\circ} \mathrm{C}$ for $3 \mathrm{~h}$. The supernatant was discarded and cells were incubated with a primary antibodies $(1: 100 ; 0.5 \mathrm{ml})$; antibodies against PDGFR- $\alpha$ (cat. no. 361162); antibodies against PDGFR- $\beta$ (cat. no. 360924; Bioworld Technology, Inc.) at room temperature for $30 \mathrm{~min}$, washed three times with PBS (3 min each) and centrifuged at $200 \mathrm{x} \mathrm{g}$ at $4^{\circ} \mathrm{C}$ for $2 \mathrm{~min}$ for collection. Subsequently, the fluorescein isothiocyanate secondary antibody (1:100; $0.5 \mathrm{ml}$; cat. no. 375702; Santa Cruz Biotechnology, Inc.) was added and the cells were incubated for $30 \mathrm{~min}$ at room temperature. Cells were then washed three times with PBS (3 min each). Cells were then fixed in $1 \%$ paraformaldehyde at room temperature for 30 min and adjusted to a concentration of $5 \times 10^{5}$ cells $/ \mathrm{ml}$ prior to analysis. PBS was utilized as a negative control for PDGFR- $\alpha$. However, PDGFR- $\beta$ has no wild-type group, so incubation using secondary antibodies alone served as the control. Flow cytometry was then performed using a Beckman Coulter flow cytometer. Results were analyzed using Win MDI 2.9 software (Bio-Rad Laboratories, Inc.).

Statistical analysis. Data were presented as the mean \pm standard deviation and three repeats were performed for each group. Statistical analysis was performed using one-way analysis of variance followed by a Student-Newman-Keuls test. The differences between the two groups were compared using a Student's t-test. Statistical analysis was performed using SPSS 13.0 software (SPSS, Inc., Chicago, IL, USA). P $<0.05$ indicated that the difference between groups was statistically significant.

\section{Results}

PT-qPCR detection of PDGF mRNA. A high dose of amygdalin significantly suppressed the mRNA expression of PDGF
A

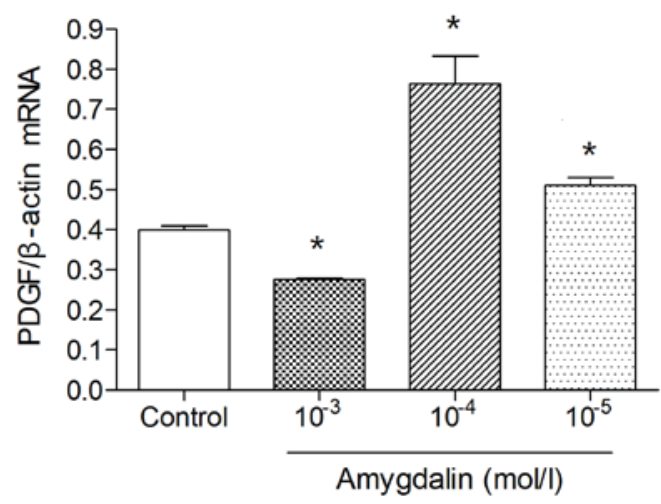

B

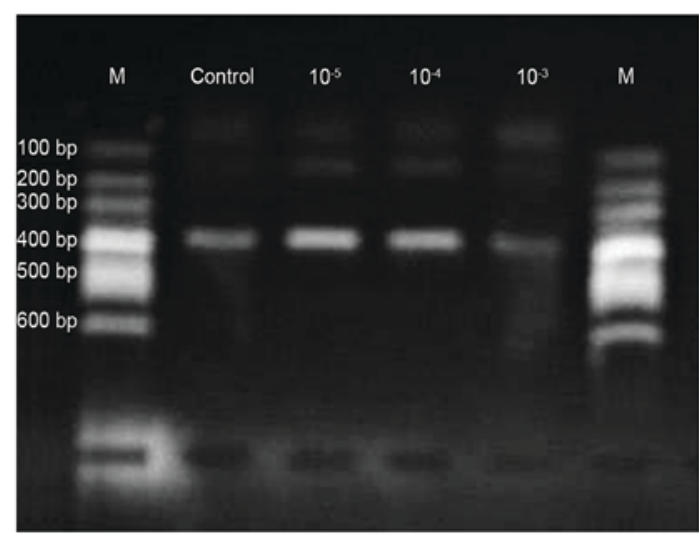

Figure 1. RT-qPCR results showing PDGF mRNA levels in the four groups. (A) RT-qPCR was used to measure the expression of PDGF mRNA. (B) HSC-T6 cells were incubated with amygdalin for $48 \mathrm{~h}$ and the PDGF mRNA levels were assessed using RT-qPCR. "P $<0.05$ vs. control. The high dose group $\left(10^{-3} \mathrm{~mol} / \mathrm{l}\right.$ amygdalin) exhibited a significant decrease compared with the control group. In addition, the low- and mid-dose groups ( $10^{-5} \mathrm{~mol} / 1$ amygdalin; $10^{-4} \mathrm{~mol} / 1$ amygdalin, respectively) exhibited a significant increase in PDGF mRNA, compared with the control group. RT-qPCR, reverse transcription quantitative polymerase chain reaction; PDGF, platelet-derived growth factor; Con, control; $10^{-5}$, low dose, $10^{-5} \mathrm{~mol} / \mathrm{l}$ amygdalin; $10^{-4}$, mid dose, $10^{-4} \mathrm{~mol} / 1$ amygdalin; $10^{-3}$, high dose, $10^{-3} \mathrm{~mol} / \mathrm{l}$ amygdalin; M, DNA marker.

compared with the control group ( $\mathrm{P}<0.05$; Fig. 1A). However, low or mid doses of amygdalin had no significant effect on suppressing PDGF mRNA expression compared with the control group. Furthermore, the mid and low dose treatments led to an increase of PDGF mRNA compared with the control group $(\mathrm{P}<0.05$; Fig. 1A). These results suggest that effect of amygdalin in suppressing the mRNA expression of PDGF is dose-dependent.

$R T$-qPCR detection of IGF mRNA. A high dose of amygdalin significantly suppressed the mRNA expression of IGF compared with the other experimental groups and the control group ( $\mathrm{P}<0.05$; Fig. 2A). Furthermore, low or mid-doses of amygdalin had no significant effect on suppressing the mRNA expression of IGF, compared with the control group. However, the mid dose treatment did lead to an increase of IGF mRNA compared with the control group (Fig. 2A). This result suggested a dose-dependent effect of amygdalin in suppressing the mRNA expression of IGF. 
A

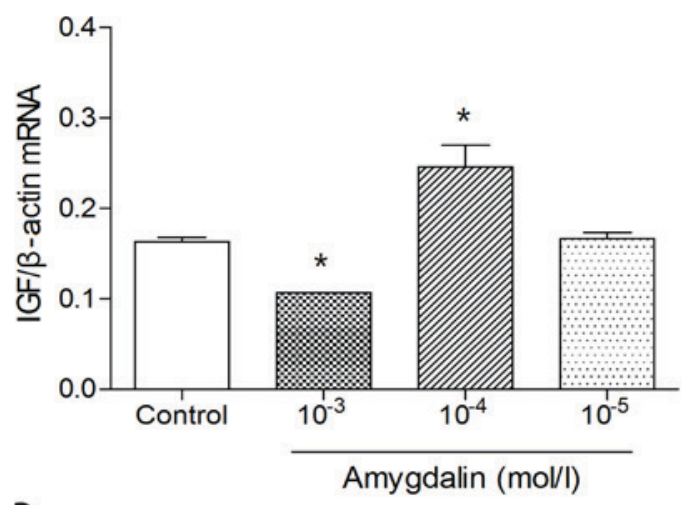

B

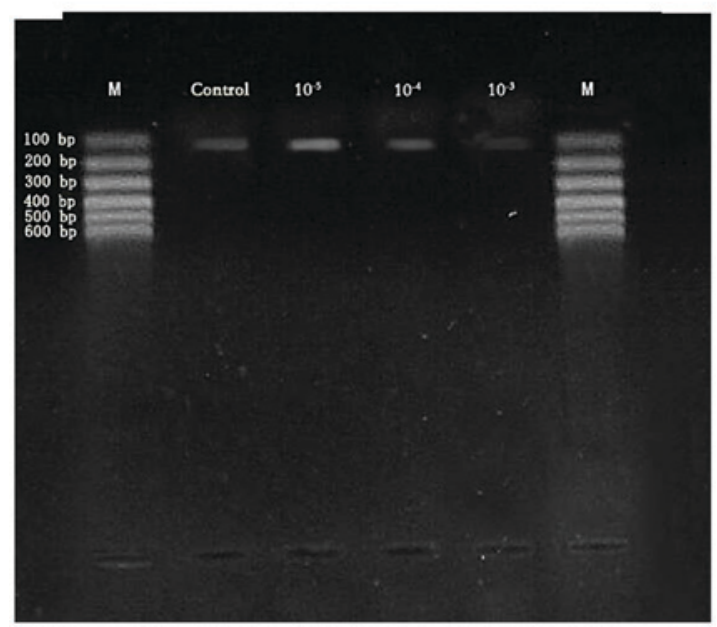

Figure 2. RT-qPCR results presenting IGF mRNA levels in the four groups. (A) RT-qPCR analysis was used to measure the expression of IGF mRNA. (B) HSC-T6 cells were incubated with amygdalin for $48 \mathrm{~h}$ and the level of IGF mRNA was assessed using RT-qPCR. "P $<0.05$ vs. Control. The high dose group $\left(10^{-3} \mathrm{~mol} / \mathrm{l}\right.$ amygdalin) exhibited a significant decrease compared with the control group. In addition, the mid dose group $\left(10^{-4} \mathrm{~mol} / \mathrm{l}\right.$ amygdalin) exhibited a significant increase in IGF mRNA, compared with the control group. RT-qPCR, reverse transcription quantitative polymerase chain reaction; IGF, insulin-like growth factor; Con, control; $10^{-5}$, low dose, $10^{-5} \mathrm{~mol} / \mathrm{l}$ amygdalin; $10^{-4}$, mid dose, $10^{-4} \mathrm{~mol} / 1$ amygdalin; $10^{-3}$, high dose, $10^{-3} \mathrm{~mol} / 1$ amygdalin; M, DNA marker.

Western blot analysis of PDGF protein. Following 24, 48 and $72 \mathrm{~h}$ of treatment, high dose and low dose amygdalin groups demonstrated decreased PDGF protein expression, compared with the control group ( $\mathrm{P}<0.05$; Fig. 3A). For all time points, the high-dose group had the least amount of PDGF protein, followed by the low-dose groups. This indicated a dose-dependent effect of amygdalin on suppressing PDGF expression.

Flow cytometry determination of PDGFR levels. Flow cytometry detected only a trace expression of PDGFRs in all groups and the effect of amygdalin on PDGFR levels was not significant compared with the control group (Figs. 4-7; Table I).

\section{Discussion}

PDGF, which is released from platelets, is a serum mitogen that serves a primary role in various processes of cell biology, including the enhancement of cell division and the control of

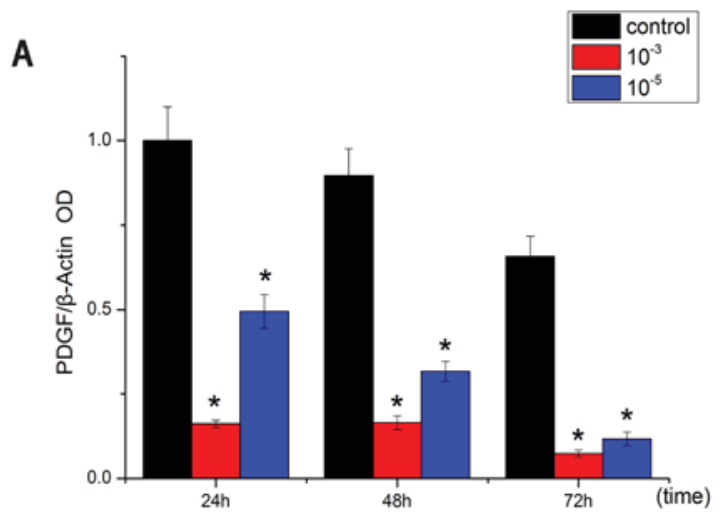

B

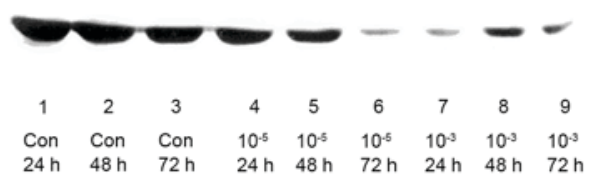

Figure 3. Western blotting results demonstrating PDGF protein levels in the three groups. HSC-T6 cells were incubated with amygdalin for 24, 48 and $72 \mathrm{~h}$. (A) Levels of PDGF protein were quantified and. (B) Analyzed using western blotting. " $\mathrm{P}<0.05$ vs. Control. PDGF, platelet-derived growth factor; Con, control; $10^{-5}$, low dose, $10^{-5} \mathrm{~mol} / 1$ amygdalin; $10^{-3}$, high dose, $10^{-3} \mathrm{~mol} / \mathrm{l}$ amygdalin.
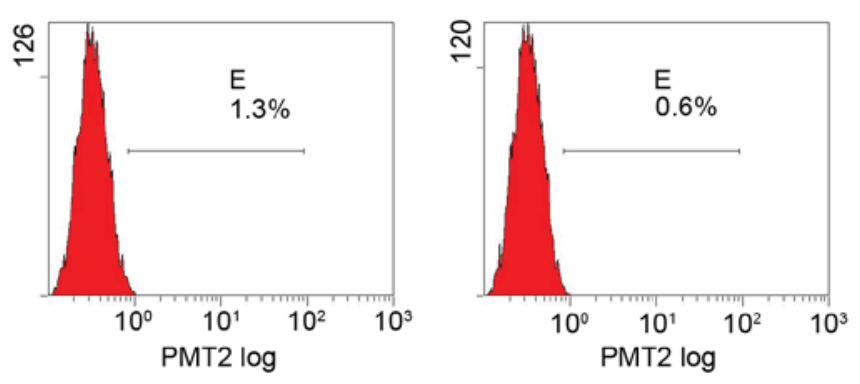

Figure 4. Expression level of platelet-derived growth factor receptor in the $10^{-5} \mathrm{~mol} / 1$ amygdalin group as analyzed using flow cytometry. PMT2, fluorescence intensity; E, percentage of positive cells.
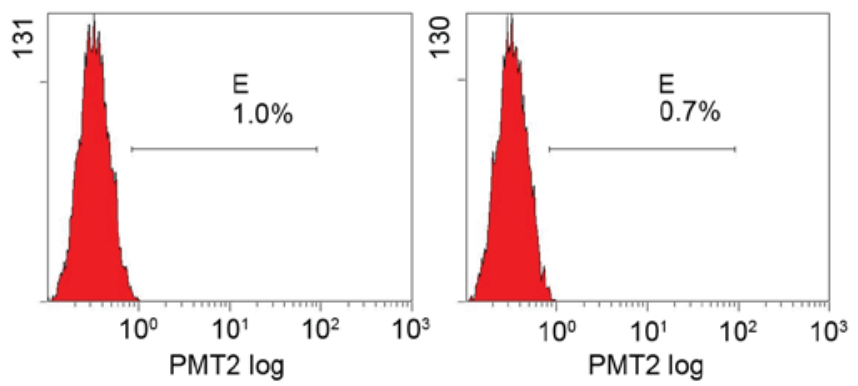

Figure 5. Expression level of platelet-derived growth factor receptor in the $10^{-4} \mathrm{~mol} / 1$ amygdalin group as analyzed using flow cytometry. PMT2, fluorescence intensity; E, percentage of positive cells.

maturation. It also affects glial cell growth and differentiation. PDGF is generated by a variety of cell types and when liver failure occurs it is predominantly secreted from nonparenchymal 
Table I. Comparison of PDGFR levels between the four groups (\%).

\begin{tabular}{lcc}
\hline Group & PDGFR- $\alpha$ & PDGFR- $\beta$ \\
\hline High dose & 1.3 & 0.6 \\
Mid dose & 1.0 & 0.7 \\
Low dose & 1.3 & 0.7 \\
Control & 1.6 & 0.8 \\
\hline
\end{tabular}

PDGFR, platelet-derived growth factor receptor.
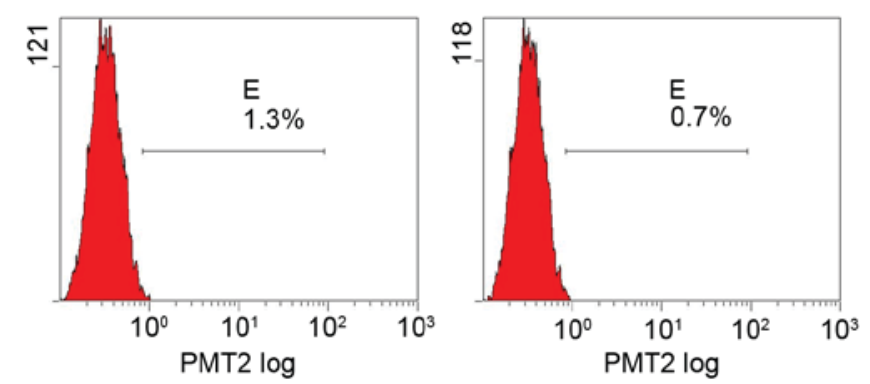

Figure 6. Expression of platelet-derived growth factor receptor in the $10^{-3} \mathrm{~mol} / 1$ amygdalin group as analyzed using flow cytometry. PMT2, fluorescence intensity; E, percentage of positive cells.
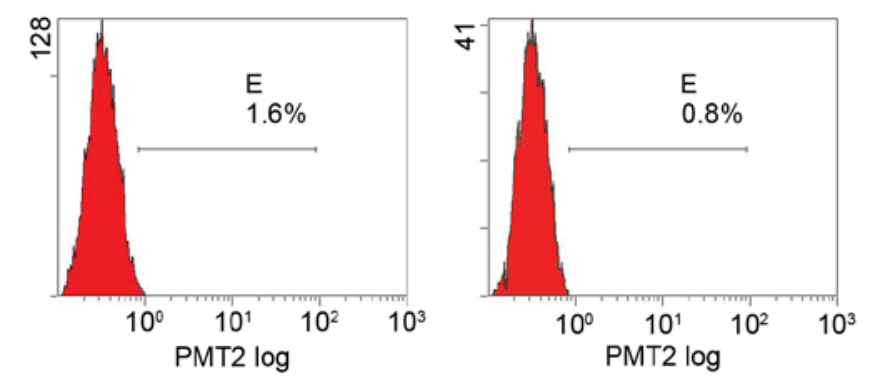

Figure 7. Expression of platelet-derived growth factor receptor in the control group as analyzed using flow cytometry. PMT2, fluorescence intensity; $\mathrm{E}$, percentage of positive cells.

cells, including Kupffer and hepatic sinusoidal endothelial cells, or from activated HSCs through autocrine and paracrine mechanisms to regulate downstream pathways $(8,9)$. PDGF serves an important role in stimulating HSC proliferation and altering its cellular skeleton distribution, thereby promoting HSCs to differentiate into myofibroblasts (MFBs) (10). In chemical terms, PDGF is a dimeric glycoprotein consisting of two A(-AA) or $\mathrm{B}(-\mathrm{BB})$ chains, or a combination of the two(-AB); therefore, PDGF has three dimeric isoforms: PDGF-AA, PDGF-BB and PDGF-AB (11). The PDGF signaling network is activated when PDGF binds to its receptor on the membrane. PDGFR is a single-strand transmembrane protein of $170-180 \mathrm{kDa}$ containing two subunits, PDGFR- $\alpha$ and PDGFR- $\beta$, which make three different combinations, PDGFR- $\alpha \alpha$, PDGFR- $\beta \beta$ and PDGFR- $\alpha \beta$ (12). As the $\alpha$ subunit is highly affinitive to the $A$ chain whereas the $\beta$ subunit is affinitive to the $\mathrm{B}$ chain, PDGFR- $\alpha \alpha$ binds only to PDGF-A,PDGFR- $\beta \beta$ to PDGF-BB and PDGFR- $\alpha \beta$ to both PDGF-BB and PDGF-AB (13). PDGF-BB and PDGFR- $\beta \beta$ have important roles in regulating liver fibrosis as PDGFR is typically expressed in the $\beta$ form and binds to PDGF-BB during liver fibrosis (14). PDGF binds to PDGFR and the dimerized receptor activates the autophosphorylation of various sites within their cytosolic domains, which serve to mediate the signal transduction (14). PDGF affects cells in various ways: i) It stimulates HSC proliferation. PDGF has no effect on unactivated HSCs, but for HSCs activated from spontaneous activation or stimulated by culturing with TGF- $\beta$ or Kupffer cell conditioned medium, PDGF is able to promote their proliferation through a dose-dependent regulation. ii) It stimulates collagen synthesis and inhibits collagen degeneration. In liver fibrosis lesions, the PDGF location is highly associated with the distribution of mononuclear macrophages and collagen-producing cells and also with the deposition of collagen types I and III (15). Furthermore, PDGF is positively associated with the tissue inhibitor of metalloproteinase-1 level, which serves an important role in degenerating ECM (15). iii) In addition to being a chemotactic factor of mononuclear macrophages, neutrophils and HSCs, PDGF also promotes HSC migration in a dose-dependent manner (16). A previous study revealed that the expression of PDGF and PDGFR are significantly higher in liver fibrosis than in normal liver tissues and its activity increased with the severity of liver fibrosis (17). Particularly, the expression of PDGF in HSCs exhibited a significant positive correlation with the level of fibrosis. This suggests that PDGF has an important role in changing HSC to MFB cells.

IGF is a polypeptide mitogen that is similar to proinsulin; therefore, it has an important role in regulating cell proliferation, differentiation and apoptosis and mediates cell growth, synthetic metabolism, glucose reduction and immune regulation (18). Pinzani and Marra (4) previously demonstrated that PDGF enhanced the secretion and release of IGF and its binding proteins in rat HSCs and also promoted HSC division and proliferation by stimulating DNA synthesis in cells. Another study revealed that exogenous IGF significantly promoted HSC proliferation, indicating that IGF may be produced through autocrine and paracrine functions of HSCs and are further associated with the repair of liver damage by promoting liver fibrosis (19).

In the present study, the mRNA expression of PDGF and IGF was significantly suppressed by the high dose of amygdalin compared with that observed in controls. Whereas the high-dose group exhibited a significant decrease compared with the control group, the low- and mid-dose groups did not suppress PDGF and IGF mRNA expression. The mid-dose treatments led to a significant increase of PDGF and IGF mRNA compared with the control group. This difference may be due to the fact that relatively low doses of amygdalin are not sufficient to transfer signals to its receptor.

In the present study, amygdalin exhibited a long-term suppressive effect on PDGF protein levels, from 24 to $72 \mathrm{~h}$. However, amygdalin treatment exhibited no significant effect on PDGFR. First, this may be associated with limitations of the experiment performed. As the fluorescence of PDGFR may be quenched easily, improper behaviors during sample handling and loading may result in false-negative results. However, due to time limitations, this could not be repeated in the present study and awaits further investigation. Second, due 
to differences between HSC-T6 and in vivo HSCs, HSC-T6 cells may fail to express PDGFR.

Therefore, the present study suggests that amygdalin reduced the production of PDGF and IGF by down regulating their transcription of genes. In this way, the influence of PDGF and IGF on HSCs may be reduced, thereby realizing the function of anti-fibrosis during the formation of liver fibrosis.

In conclusion, amygdalin is able to reduce the transcription of PDGF and IGF mRNA and the expression of PDGF protein. Amygdalin also decreased the synthesis and release of PDGF and IGF, thereby reducing the influence of PDGF and IGF on HSCs, thus protecting the liver from fibrosis. IGF and PDGF have been identified as significant mitogens for liver myofibroblasts (LMFs), a cell population that serves a role in liver fibrogenesis. A previous study demonstrated that both IGF-I and PDGF are important growth-promoting factors of LMFs in vitro (10). In the present study, amygdalin reduced the transcription of PDGF and IGF mRNA and the expression of PDGF protein. Furthermore, amygdalin also decreased the synthesis and release of PDGF and IGF. The data presented herein indicates that IGF and PDGF serve important roles in liver fibrogenesis, such that these may be attractive targets for future antifibrotic therapy.

\section{Acknowledgements}

Not applicable.

\section{Funding}

The presentstudy was supported by Guangdong Province Natural Science Foundation of China (grant no. S2012010008917).

\section{Availability of data and materials}

The datasets used and/or analyzed during the present study are available from the corresponding author on reasonable request.

\section{Authors' contributions}

Not applicable.

\section{Ethics approval and consent to participate}

Not applicable.

\section{Consent for publication}

Not applicable.

\section{Competing interests}

The authors declare that they have no competing interests.

\section{References}

1. Lee UE and Friedman SL: Mechanisms of hepatic fibrogenesis. Best Pract Res Clin Gastroenterol 25: 195-206, 2011.

2. Yoshiji H, Kuriyama S, Noguchi R, Ikenaka Y, Yoshii J, Yanase K, Namisaki T, Kitade M, Yamazaki M, Asada K, et al: Amelioration of liver fibrogenesis by dual inhibition of PDGF and TGF-beta with a combination of imatinib mesylate and ACE inhibitor in rats. Int J Mol Med 17: 899-904, 2006.
3. Di Sario A, Bendia E, Svegliati-Baroni G, Marzioni M, Ridolfi F, Trozzi L, Ugili L, Saccomanno S, Jezequel AM and Benedetti A: Rearrangement of the cytoskeletal network induced by platelet-derived growth factor in rat hepatic stellate cells: Role of different intracellular signaling pathways. J Hepatol 36: 179-190, 2002.

4. Pinzani M and Marra F: Cytokine receptors and signaling in hepatic stellate cells. Semin Liver Dis 21: 397-416, 2001.

5. Puche JE, Saiman Y and Friedman SL: Hepatic stellate cells and liver fibrosisi. Compr Physiol 3: 1473-1492, 2013.

6. Livak KJ and Schmittgen TD: Analysis of relative gene expression data using real-time quantitative PCR and the 2(-Delta DeltaC(T)) method. Methods 25: 402-408, 2001.

7. Wang W, Huang XR, Li AG, Liu F, Li JH, Truong LD, Wang XJ and Lan HY: Signaling mechanism of TGF-betal in prevention of renal inflammation: Role of Smad7. J Am Soc Nephrol 16: 1371-1383, 2005.

8. Burt AD: C L Oakley Lecture (1993) Cellular and molecular aspects of hepatic fibrosis. J Pathol 170: 105-114, 1993.

9. Wong L, Yamasaki G, Johnson RJ and Friedman SL: Induction of beta-platelet-derived growth factor receptor in rat hepatic lipocytes during cellular activation in vivo and in culture. J Clin Invest 94: 1563-1569, 1994.

10. Di Sario A, Bendia E, Svegliati-Baroni G, Marzioni M, Ridolfi F, Trozzi L, Ugili L, Saccomanno S, Jezequel AM and Benedetti A: Rearrangement of the cytoskeletal network induced by platelet-derived growth factor in rat hepatic stellate cells: Role of different intracellular signalling pathways. J Hepatol 36: 179-190, 2002

11. Ge X, Chen S, Liu M, Liang T and Liu C: Evodiamine attenuates PDGF-BB-induced migration of rat vascular smooth muscle cells through activating PPAR $\gamma$. Int J Mol Sci 16: 28180-28093, 2015.

12. Kuai J, Mosyak L, Brooks J, Cain M, Carven GJ, Ogawa S, Ishino T, Tam M, Lavallie ER, Yang Z, et al: Characterization of binding mode of action of a blocking anti-platelet-derived growth factor (PDGF)-B monoclonal antibody, MOR8457, reveals conformational flexibility and avidity needed for PDGF-BB to bind PDGF receptor- $\beta$. Biochemistry 54: 1918-1929, 2015.

13. Pinzani M, Milani S, Herbst H, DeFranco R, Grappone C, Gentilini A, Caligiuri A, Pellegrini G, Ngo DV, Romanelli RG and Gentilini P: Expression of platelet-derived growth factor and its receptors in normal human liver and during active hepatic fibrogenesis. Am J Pathol 148: 785-800, 1996.

14. Rong R, Wang YC, Hu LQ, He QQ, Zhou XF, Wang TH and Bu PL: Role of endogenous PDGF-BB in cultured cardiomyocytes exposed to hypoxia. Neuropeptides 50: 43-49, 2015.

15. Borkham-Kamphorst E and Weiskirchen R: The PDGF system and its antagonists in liver fibrosis. Cytokine Growth Factor Rev 28: 53-61, 2016.

16. Carloni V, Romanelli RG, Pinzani M, Laffi G and Gentilini P: Focal adhesion kinase and phospholipase C gamma involvement in adhesion and migration of human hepatic stellate cells. Gastroenterology 112: 522-531, 1997.

17. Cao S, Yaqoob U, Das A, Shergill U, Jagavelu K, Huebert RC, Routray C, Abdelmoneim S, Vasdev M, Leof E, et al: Neuropilin-1 promotes cirrhosis of the rodent and human liver by enhancing PDGF/TGF-beta signaling in hepatic stellate cells. J Clin Invest 120: 2379-2394, 2010.

18. Jiang G, Wang W, Cao Q, Gu J, Mi X, Wang K, Chen G and Wang X: Insulin growth factor-1 (IGF-1) enhances hippocampal excitatory and seizure activity through IGF-1 receptor-mediated mechanisms in the epileptic brain. Clin Sci (Lond) 129: 1047-1060, 2015

19. Gentilini A, Marra F, Gentilini $P$ and Pinzani M: Phosphatidylinositol-3 kinase and extracellular signal-regulated kinase mediate the chemotactic and mitogenic effects of insulin-like growth factor-I in human hepatic stellate cells. J Hepatol 32: 227-234, 2000.

(i) $($ This work is licensed under a Creative Commons Attribution-NonCommercial-NoDerivatives 4.0 International (CC BY-NC-ND 4.0) License. 